\title{
Evaluation of Urinary Cytokines in Idiopathic Glomerulonephritis in a Tertiary Care Teaching Hospital
}

\author{
Deba Prasad Kar ${ }^{1}$, Vijay Pratap Singh ${ }^{2 \star}$, Anupam Agarwal ${ }^{3}$, Vivek C Ganiger ${ }^{4}$, Jatindra Nath Mohanty ${ }^{5}$ \\ 'Department of Nephrology, IMS and SUM hospital, Siksha "O” Anusandhan University (Deemed to be), K8, Kalinga nagar, Bhubaneswar-751003, Odisha, \\ India, ${ }^{2}$ Consultant nephrologists Gorakhpur, Uttar Pradesh, India, ${ }^{3}$ Dept Nephrology VMMC and Safdarjang Hospital, New Delhi, 110029, India, \\ ${ }^{4}$ Department of Nephrology, Karnataka Institute of Medical Sciences, Hubli, Karnataka, India ${ }^{5}$ Medical Research Laboratory, IMS and SUM hospital, \\ Siksha "O" Anusandhan University (Deemed to be), K8, Kalinga nagar,Bhubaneswar-751003, Odisha, India.
}

\section{Abstract}

Background: Idiopathic primary glomerular diseases include a group of disorders characterized by pathologic alterations in normal glomerular structure and function, independent of systemic disease processes. Inflammatory cytokines, including MCP-1 and IL-6, plays an important role in glomerular inflammation. In this study we determined whether the measurement of urinary MCP-1 and IL- 6 might be useful in assessing the role of these urinary marker in idiopathic primary glomerulonephritis and its relationship with histopathological finding. We found in result the minimum level of MCP-1 and IL-6 was $5.6 \mathrm{pg} / \mathrm{ml}$ and $7.69 \mathrm{pg} / \mathrm{ml}$ and the maximum level of MCP-1 and IL-6 was $23.6 \mathrm{pg} / \mathrm{ml}$ and $60.04 \mathrm{pg} / \mathrm{ml}$ respectively. The mean and standard deviation were higher in nephrotic range proteinuria than nonnephrotic proteinria. Correlation of urinary MCP-1 and IL- 6 with 24 hour urinary protein $<3.5 \mathrm{gm}$ and $\geq 3.5 \mathrm{gm}$ were analysed. The correlation between urinary IL-6 and histopathological finding of idiopathic primary glomerular diseases were found statiscally significant ( $p$ value $<0.05$ ). In conclusion, we found that level of urinary MCP-1 was raised in patients with increase degree of interstitial fibrosis and tubulointerstitial infiltrates and urinary IL-6 was noted in high level increase with increase degree of glomerlosclerosis, interstitial fibrosis and tublar atrophy.

Keywords: Urinary cytokines, Glomerulonephritis, MCP-1, IL-6.

Corresponding Author: Dr. Vijay Pratap Singh, Consultant nephrologists, Gorakhpur, Uttar Pradesh, 273001, India.

Received: October 2019

Accepted: October 2019

\section{Introduction}

Idiopathic primary glomerular diseases include a group of disorders characterized by pathologic alterations in normal glomerular structure and function, independent of systemic disease processes. Glomerular diseases, including idiopathic glomerulonephritis, are major causes of end-stage kidney disease (ESKD). Clinically, they are manifested with haematuria, proteinuria and declining kidney function. Histopathologically, they are associated with inflammation and proliferation of the glomerular tissue and enhanced glomerular and interstitial production of inflammatory mediators, such as monocyte chemoattractant protein-1 (MCP-1) $)^{[1,2]}$ and IL-6.

Inflammatory cytokines, including $\mathrm{MCP}-1$, play an important role in glomerular inflammation. MCP-1 is produced by macrophages, vascular endothelial cells, monocytes and fibroblasts. It triggers migration and retention of monocytes and transformation of fibroblasts in the glomeruli. ${ }^{[3]}$ The urinary concentration of MCP-1 increases with increased activity of glomerular diseases (GN). Interleukin (IL)-6 is produced in vitro by monocytes/ macrophages, neutrophils, and endothelial, mesangial and epithelial cells [4]. IL-6 is a multifunctional cytokine; it stimulates in vitro proliferation of fibroblasts and mesangial cells, ${ }^{[5]}$ but also is implicated in the fibrogenetic process in variable diseases, particularly of the kidneys and lungs. ${ }^{[6]}$ Mesangial cell proliferation and glomerular matrix accumulation may also contribute to the development of glomerulosclerosis independent of the underlying primary disease.

Increased urinary IL-6 excretion has been detected in a variety of renal abnormalities and several patients with mesangial hypercellularity failed to excrete detectable urinary IL-6. ${ }^{[7]}$ Therefore, the study of factors that drive mesangial cell proliferation and matrix production is important to understand the pathogenesis and to design new therapeutic approaches for mesangioproliferative glomerulonephritis and progressive glomerulosclerosis. So in this present study we analyzed the urinary MCP-1 and IL-6 in primary glomerular diseases and correlate the association of urinary MCP-1 and IL-6 with the severity of histopathological finding in idiopathic primary glomerular diseases.

\section{Subjects and Methods}

This study was conducted in the department of nephrology, Institute of Medical Sciences and Sum hospital, 
Bhubaneswar from January 2018 to June 2019 and during this period we enrolled 30 patients of biopsy proven idiopathic glomerulonephritis. Patients with lesions of idiopathic primary glomerulonephritis (membranous nephropathy, focal segmental glomerulosclerosis, membranoproliferative glomerulonephritis and minimal change disease) diagnosed on light microscopy and immunofluorosecence of renal biopsy specimens were included in the study. The patients having the following features were excluded: Inability to obtain informed consent, coexistent septicemia, dialysis dependent state, secondary glomerulonephritis, active urinary tract infection.

The patient's detailed history, demographic details, clinical findings and laboratory reports were recorded on a predesigned, pretested and structured performa. Relevant blood and urine investigations were done at the time of diagnosis.

\section{Renal Biopsy}

Following renal biopsy, two biopsy tissues were sent to renal pathology lab.

\section{Light Microscopy}

For light microscopy biopsy tissue sent in $10 \%$ formalin. Tissue for light microscopy processed in to paraffin blocks section was stained with hematoxylin and eosin, periodic acid Schiff, Gamori trichrome and AFOG stains.

\section{Immuno Fluorescence Microscopy}

For immunofluorescence biopsy tissue sent in normal saline. Tissue for immunofluorescence section cutting done with cryostat, was fixed in chilled acetone for $2 \mathrm{~min}$, stained with immunofluorescence stain (FITC conjugate poured over tissue over $30 \mathrm{~min}$ ), washed with phosphate buffer saline, mount by wet mount technique and was observed in fluorescence microscope.

\section{Urinary MCP-1and IL-6}

\section{Sample Collection and Storage}

Freshly voided urine samples were collected in $5 \mathrm{ml}$ vials. Simultaneous urine culture were done to rule out infection and if culture were positive then urine discarded. In the laboratory these samples were centrifuged to remove sediment and stored at $-20^{\circ} \mathrm{C}$ for later chemokine analysis.

\section{Methodology for Estimation of Urinary MCP-1}

MCP was measured by Enzyme Linked Immunosorbent Assay using human MCP-1 ELISA kit (Elabscience, Wuhan,P.R.C.). The procedure was done according to the manufactures direction. The minimum detectable limit of human MCP-1 was $9.38 \mathrm{pg} / \mathrm{ml}$ for this kit and detection range was $15.63-1000 \mathrm{pg} / \mathrm{ml}$. The coefficient of variation was $<10 \%$.

\section{Statistical Analysis}

Data analysis was done through SPSS 16.0 Software. The association were obtained by student $t$-test. A $p$ value $<0.05$ considered as significant.

\section{Results}

we enrolled 30 patients of biopsy proven idiopathic glomerulonephritis. The sex ratio (M:F) in our study was 3:2 $(\mathrm{n}=18$ and $\mathrm{n}=12$ in male and female respectively). Most common age group was affected $20-29$ years $(30 \%)$ and out of this $23.33 \%(n=7)$ and $6.66 \%(n=2)$ were male and female respectively. This was followed by $10-19$ years $(23.33 \%)$ age group in $13.33 \%$ (4) and $10 \%$ (3) respectively in male and female.

\section{Basic disease of study patients}

Table-1 showing the basic disease pattern of idiopathic primary glomerular disease in this study patients. It is observed that most common disease was FSGS (46.67\%) and out of this $26.67 \%(n=8)$ and $20 \%(n=6)$ were male and female respectively. FSGS was seen in the age group of 1545 years in this study and most commonly affected was 20 30 years. It was followed by membranous nephropathy $(33.33 \%)$ out of which $20 \%(n=6)$ were male and $13.33 \%$ $(n=4)$ were female. The age group of membranous nephropathy were 30-60 years in this study and most of MN patients were in 40-60 years age. MN followed by MPGN (13.33) in which $10 \%(n=3)$ and $3.33 \%(n=)$ were male and female. MCD was in $6.67 \%(n=2)$ cases.

Table 1: Basic disease of study patients

\begin{tabular}{|l|l|l|l|l|}
\hline Disease & $\begin{array}{l}\text { Age } \\
\text { (years) }\end{array}$ & Male (\%) & $\begin{array}{l}\text { Female } \\
(\mathbf{\%})\end{array}$ & Total (\%) \\
\hline MCD & $15-20$ & $1(3.33)$ & $1(3.33)$ & $2(6.67)$ \\
\hline MN & $30-60$ & $6(20)$ & $4(13.33)$ & $10(33.33)$ \\
\hline FSGS & $15-45$ & $8(26.67)$ & $6(20)$ & $14(46.67)$ \\
\hline MPGN & $13-21$ & $3(10)$ & $1(3.33)$ & $4(13.33)$ \\
\hline Total & & $18(60)$ & $12(40)$ & $30(100)$ \\
\hline
\end{tabular}

24 hour urinary protein in study patients:

It was observed in our study which shown in table. 2 that majority $(n=18,60.00 \%)$ of patients were in range of 3.5 to $7.9 \mathrm{gm} / 24$ hours followed by $<3.5 \mathrm{gm}$ in $33.33 \%(\mathrm{n}=10)$ patients and proteinuria of $\geq 8 \mathrm{gm}$ were seen in $6.67 \%(\mathrm{n}=2)$ patients.

Table 2: 24 Hours Urinary Protein

\begin{tabular}{|l|l|}
\hline $\mathbf{2 4}$ Hours urinary protein $(\mathbf{g m})$ & No. of patients $(\%)$ \\
\hline$<3.5$ & $10(33.33)$ \\
\hline $3.5 .0-7.9$ & $18(60.00)$ \\
\hline$\geq 8$ & $2(6.67)$ \\
\hline
\end{tabular}

Different histological finding in idiopathic primary glomerular disease in study patients:

[Table-3] showing different histological pattern of idiopathic primary glomerular disease in this study; glomerulosclerosis and interstitial fibrosis were found in equal number of patients $(n=9,30.00 \%)$ and followed by mesangial matrix expansion in $26.66 \%(\mathrm{n}=8)$, mesangial hypercellularity in $23.33 \%(\mathrm{n}=7)$, tubular atrophy in $23.33 \% \quad(\mathrm{n}=7)$, tubulointerstitial infiltrates in $13.33 \% \quad(\mathrm{n}=4)$ and endocapillary proliferation in $3.33 \%(\mathrm{n}=1)$.

Table 3: Different histological finding in idiopathic primary glomerular disease in study patients

\begin{tabular}{|l|l|}
\hline \multicolumn{1}{|c|}{ Histological finding } & No. of patients(Total=30) \\
\hline Mesangial hypercellularity & $7(23.33 \%)$ \\
\hline Mesangial matrix expansion & $8(26.66 \%)$ \\
\hline Glomerulosclerosis & $9(30.00 \%)$ \\
\hline Endocapillary proliferation & $1(3.33 \%)$ \\
\hline Interstitial fibrosis & $9(30.00 \%)$ \\
\hline Tubular atrophy & $7(23.33 \%)$ \\
\hline Tubulointerstitial infiltrates & $4(13.33 \%)$ \\
\hline
\end{tabular}


Urinary MCP-1 and IL-6 in idiopathic primary glomerular disease

In our study the minimum level of MCP-1 and IL-6 was $5.6 \mathrm{pg} / \mathrm{ml}$ and $7.69 \mathrm{pg} / \mathrm{ml}$ and the maximum level of MCP-1 and IL-6 was $23.6 \mathrm{pg} / \mathrm{ml}$ and $60.04 \mathrm{pg} / \mathrm{ml}$ respectively. Table4 was showing mean and standard deviation of MCP-1 and IL-6 in idiopathic primary glomerular diseases and higher level were seen in MN, FSGS and MPGN than MCD.

Table 4: Urinary MCP-1 and IL-6 in idiopathic primary glomerular disease

\begin{tabular}{|l|c|c|}
\hline Diagnosis & $\begin{array}{c}\text { MCP-1(pg/ml) } \\
\text { Mean } \pm \text { SD }\end{array}$ & $\begin{array}{c}\text { IL-6(pg/ml) } \\
\text { Mean } \pm \text { SD }\end{array}$ \\
\hline MCD & $7.69 \pm 0$ & $7.79 \pm 0.141$ \\
\hline MN & $13.40 \pm 7.87$ & $15.34 \pm 11.10$ \\
\hline FSGS & $13.07 \pm 5.40$ & $23.68 \pm 14.48$ \\
\hline MPGN & $19.39 \pm 5.25$ & $25.42 \pm 10.89$ \\
\hline
\end{tabular}

Correlation of urinary MCP-1 and IL-6 with 24 hour urinary protein;

Correlation of urinary MCP-1 and IL-6 with 24 hour urinary protein $<3.5 \mathrm{gm}$ and $\geq 3.5 \mathrm{gm}$ were shown in table- 5 . The mean and standard deviation were higher in nephrotic range proteinuria than nonnephrotic proteinria. The p-value $(<0.05)$ were statistically significant in both MCP-1 and IL-6.

Table 5: Correlation of urinary MCP-1 and IL-6 with 24 hour urinary protein

\begin{tabular}{|l|l|l|c|l|l|}
\hline \multirow{2}{*}{$\begin{array}{l}24 \\
\text { urinary } \\
\text { protein }\end{array}$} & $\begin{array}{l}\text { Number } \\
\text { of } \\
\text { patients } \\
\end{array}$ & \multicolumn{2}{|c|}{ MCP-1(pg/ml) } & \multicolumn{2}{|c|}{ IL-6(pg/ml) } \\
\cline { 3 - 5 } & Mean \pm SD & $\begin{array}{c}\text { P } \\
\text { value }\end{array}$ & Mean \pm SD & $\begin{array}{l}\text { P } \\
\text { value }\end{array}$ \\
\hline$<3.5 \mathrm{gm}$ & $10(33.33)$ & $8.69 \pm 1.98$ & 0.001 & $11.56 \pm 3.40$ & 0.008 \\
& & & $24.42 \pm 14.04$ & \\
\hline
\end{tabular}

Correlation of microscopic hematuria with urinary MCP-1 and IL-6:

The correlation between hematuria with MCP-1 and IL-6 was shown in table-6. The higher level was seen in patients with hematuria. The $\mathrm{p}$-value were statistically significant $(<0.05)$ in both MCP-1 and IL-6.

Table 6: Correlation of microscopic hematuria with urinary MCP-1 and IL-6

\begin{tabular}{|c|c|c|c|c|c|}
\hline \multirow[t]{2}{*}{$\begin{array}{l}\text { Microscopic } \\
\text { hematuria }\end{array}$} & \multirow{2}{*}{$\begin{array}{l}\text { Number } \\
\text { of } \\
\text { patients } \\
(\%)\end{array}$} & \multicolumn{2}{|l|}{$\begin{array}{c}\text { MCP- } \\
1(\mathrm{pg} / \mathrm{ml})\end{array}$} & \multicolumn{2}{|c|}{ IL-6(pg/ml) } \\
\hline & & $\begin{array}{c}\text { Mean } \pm \\
\text { SD }\end{array}$ & $\begin{array}{c}P \\
\text { value }\end{array}$ & Mean \pm SD & $\begin{array}{c}\mathbf{P} \\
\text { value }\end{array}$ \\
\hline Absent & $22(73.67)$ & $12.41 \pm 6.34$ & \multirow[t]{2}{*}{0.042} & $16.88 \pm 10.20$ & \multirow[t]{2}{*}{0.014} \\
\hline Present & $8(26.33)$ & $17.89 \pm 5.82$ & & $29.62 \pm 15.95$ & \\
\hline
\end{tabular}

Correlation of urinary MCP-1 with histopathological finding:

The correlation between urinary MCP-1 and histopathological finding of idiopathic primary glomerular diseases were shown in table-7. The p-value were significant $(<0.05)$ in cases of interstitial fibrosis and tubulointerstitial infiltrates.
Table 7: Correlation of urinary MCP-1 with histopathological finding

\begin{tabular}{|c|c|c|c|c|}
\hline \multicolumn{2}{|l|}{ Histological finding } & \multirow{2}{*}{\begin{tabular}{|l|}
$\begin{array}{l}\text { No. of } \\
\text { patients }\end{array}$ \\
23 \\
\end{tabular}} & \multirow{2}{*}{$\begin{array}{l}\text { MCP } \\
\text { 1(pg/ml) } \\
\text { Mean } \pm \text { SD } \\
13.89 \pm 7.07\end{array}$} & \multirow{2}{*}{$\begin{array}{c}\begin{array}{c}\mathbf{P} \\
\text { value }\end{array} \\
0.978\end{array}$} \\
\hline \multirow{2}{*}{$\begin{array}{l}\text { Mesangial } \\
\text { hypercellularity }\end{array}$} & Absent & & & \\
\hline & Present & 7 & $13.81 \pm 5.11$ & \\
\hline \multirow{2}{*}{$\begin{array}{l}\text { Mesangial matrix } \\
\text { expansion }\end{array}$} & Absent & 22 & $14.14 \pm 7.11$ & \multirow[t]{2}{*}{0.717} \\
\hline & Present & 8 & $13.13 \pm 5.20$ & \\
\hline \multirow[t]{2}{*}{ Glomerulosclerosis } & Absent & 21 & $12.44 \pm 6.44$ & \multirow[t]{2}{*}{0.068} \\
\hline & Present & 9 & $17.21 \pm 5.89$ & \\
\hline \multirow[t]{2}{*}{ Interstitial fibrosis } & Absent & 21 & $10.77 \pm 4.91$ & \multirow[t]{2}{*}{0.001} \\
\hline & Present & 9 & $21.11 \pm 3.55$ & \\
\hline \multirow[t]{2}{*}{ Tubular atrophy } & Absent & 23 & $13.70 \pm 6.83$ & \multirow[t]{2}{*}{0.801} \\
\hline & Present & 7 & $14.44 \pm 6.13$ & \\
\hline \multirow{2}{*}{$\begin{array}{l}\text { Tubulointerstitial } \\
\text { infiltrates }\end{array}$} & Absent & 4 & $12.68 \pm 6.12$ & \multirow[t]{2}{*}{0.005} \\
\hline & Present & 26 & $22.14 \pm 1.02$ & \\
\hline
\end{tabular}

Table 8: Correlation of urinary IL-6 with histopathological finding

\begin{tabular}{|l|l|l|l|c|}
\hline \multicolumn{2}{|l|}{ Histological finding } & $\begin{array}{l}\text { No. of } \\
\text { patients }\end{array}$ & $\begin{array}{c}\text { IL-6 (pg/ml) } \\
\text { Mean } \pm \text { (SD) }\end{array}$ & $\begin{array}{c}\text { P } \\
\text { value }\end{array}$ \\
\hline \multirow{2}{*}{$\begin{array}{l}\text { Mesangial } \\
\text { hypercellularity }\end{array}$} & Absent & 23 & $18.53 \pm 12.99$ & 0.231 \\
\cline { 2 - 4 } & Present & 7 & $25.38 \pm 12.81$ & \\
\hline $\begin{array}{l}\text { Mesangial matrix } \\
\text { expansion }\end{array}$ & Absent & 22 & $19.66 \pm 13.98$ & \multirow{2}{*}{0.747} \\
\cline { 2 - 4 } & Present & 8 & $21.44 \pm 10.89$ & \\
\hline Glomerulosclerosis & Absent & 21 & $14.01 \pm 6.43$ & \multirow{2}{*}{0.001} \\
\cline { 2 - 4 } & Present & 9 & $34.40 \pm 13.72$ & \\
\hline \multirow{2}{*}{ Interstitial fibrosis } & Absent & 21 & $15.54 \pm 8.66$ & \multirow{2}{*}{0.002} \\
\cline { 2 - 4 } & Present & 9 & $30.84 \pm 15.71$ & \\
\hline Tubular atrophy & Absent & 23 & $16.82 \pm 12.14$ & \multirow{2}{*}{0.009} \\
\cline { 2 - 4 } & Present & 7 & $31.00 \pm 10.25$ & \\
\hline \multirow{2}{*}{$\begin{array}{l}\text { Tubulointerstitial } \\
\text { infiltrates }\end{array}$} & Absent & 4 & $18.40 \pm 12.04$ & 0.063 \\
\cline { 2 - 4 } & Present & 26 & $31.38 \pm 15.93$ & \\
\hline
\end{tabular}

\section{Correlation of urinary IL-6 with histopathological finding;}

The correlation between urinary IL-6 and histopathological finding of idiopathic primary glomerular diseases were shown in table 8 . The $\mathrm{p}$ value were significant $(<0.05)$ in cases of glomerulosclerosis, interstitial fibrosis and tubular atrophy.

\section{Discussion}

Idiopathic primary glomerular diseases include a group of disorders characterized by pathologic alterations in normal glomerular structure and function, independent of systemic disease processes. Glomerulonephritis is common cause of end stage renal disease. However, it should be noted that the same primary glomerular disease as diagnosed on pathologic grounds may manifest differently in patients, from the benign to the severe. Different histological finding was observed including mesangial hypercellularity $23.33 \%(\mathrm{n}=7)$, mesangial matrix expansion $26.66 \% \quad(\mathrm{n}=8)$, glomerulosclerosis $30.00 \%(\mathrm{n}=9)$, endocapillary proliferation $3.335(\mathrm{n}=1)$, interstitial fibrosis $30.00 \%(\mathrm{n}=9)$, tubular atrophy $23.33 \%(\mathrm{n}=7)$ and tubulointerstitial infiltrates $13.33 \%(\mathrm{n}=4)$ were present. The mesangial hypercellularity and mesangial matrix expansion were not seen in the cases of MN and MCD. MCD was normal by light microscopy. In our study showed that mean and standard deviation of MCP-1 and IL-6 were higher in cases of MN, FSGS and MPGN as compared to MCD. Similar study by Brad H. et al observed that moderately elevated MCP-1 level in patients with diseases such as MN, FSGS, MPGN and IgA nephropathy. ${ }^{[1]}$ A 
review by Silva ACS. et al reported in regard to glomerular diseases, high urinary levels of CCL2/MCP-1 have been frequently related to FSGS, lupus nephritis, and $\operatorname{IgA}$ nephropathy. ${ }^{[8]}$ A study by Horn $\mathrm{Y}$ et al revealed that glomerular IL-6 overexpression was detected in human glomerulonephritis types characterized by mesangial hypercellularity such as IgA nephropathy and some types of lupus nephritis. Hrvacevic R et al found that IL-6 was elevated in the urine of 30 patients with different histological types of glomerular lesions (range 3.7 to $433.3 \mathrm{pg} / \mathrm{ml}$ ) but was not detected in the urine of remaining 13 patients which seems to be similar finding like our study. They concluded that urinary IL-6 level can be considered as a marker of glomerulonephritis but not one that is very specific for any particular histological type of primary glomerulonephritis [9]. MCP-1and IL-6 are produced locally in the kidney are directly related to the extent of histolological changes. Thus, the urinary MCP-1and IL-6 level is not a useful tool in the differential diagnosis of primary glomerulonephritis.

Our study showed that mean and standard deviation of both urinary MCP-1 and IL-6 was higher in patients with nephrotic range proteinuria $(\geq 3.5 \mathrm{gm})$ than subnephrotic range proteinuria $(<3.5 \mathrm{gm})$ and it was statistically significant (p-value of MCP-1 and IL-6 was 0.001 and 0.008 respectively). Therefore increase in urinary level of these biomarker correlate with increase in urinary protein excretion. A similar study by Brad $\mathrm{H}$. et al showed that urinary MCP-1 correlated with urinary protein excretion(pvalue $<0.0001) .{ }^{[1]}$ A study by Rafid $\mathrm{T}$. et al, urinary MCP-1 in idiopathic glomerulonephritis; in which urinary albumin creatinine ratio (ACR) was used as reliable marker of proteinuria. Urinary MCP-1 level was correlated with ACR (p-value $=0.01) \cdot{ }^{[10]} \mathrm{A}$ study by Maria Stangou et al showed that severity of proteinuria had significant positive correlation with urinary excretion of IL-6 $(\mathrm{p}$-value $=0.001)$ and MCP-1 (p-value $=<0.001)$. The close relationship between cytokines (MCP-1 and IL-6) excretion and proteinuria may indicate that protein overload is the major stimulus that leads to tubular cell activation with cytokine production, inflammation and subsequent tissue damage.A study by Minghui Song et al showed positive correlation between 24 hour urinary protein and urinary IL-6 level. ${ }^{[11]}$

Our study it was observed that mean and standard deviation of urinary MCP-1 and IL-6 was higher in patients with microscopic hematuria than patients not having microscopic hematuria and it was statistically significant (pvalue of MCP-1 and IL-6 was 0.042 and 0.014 respectively).. A study by Minghui Song, et al reported that urinary IL-6 levels had a high positive correlation with protein quantity in the renal hematuria with proteinuria $>1,000 \mathrm{mg} / 24 \mathrm{~h}$ group. ${ }^{[11]}$ Silva ACS. et al showed urinary concentrations of MCP-1 had significant positive correlation with microscopic hematuria. ${ }^{[8]}$ Abnormal IL-6 secretion promotes the hyperplasia of mesangial cells and matrix and, thus, affects the permeability of the glomerular filtration membrane ${ }^{[11]}$ Under pathological conditions, the distribution of interleukin-6 (IL-6) in kidney tissue is abnormal and urinary IL-6 levels are increased. Therefore increase in level of these urinary biomarker positively correlated with microscopic hematuria in idiopathic glomerulonephritis. However, the detection of urinary MCP-1and IL-6 levels in patients with renal hematuria is beneficial for disease evaluation. In our study observed that urinary level of MCP1 positively correlated ( $\mathrm{p}$-value $=0.001$ and 0.005 in interstitial fibrosis and tubulointerstitial infiltrates respectively) with degree of interstitial fibrosis and tubulointerstitial infiltrates. A previous study by Maria Stangou et al showed that urinary level of MCP-1 correlated with degree of interstitial fibrosis. ${ }^{[12]} \mathrm{Brad} \mathrm{H}$. et al reported that Urinary MCP-1 levels were significantly higher in patients with active glomemlar lesions compared with patients with patients with histologic findings of active glomerular injury (crescents, necrosis, or endocapillary proliferation) than in patients with less active glomerular lesions (mesangial expansion, mesangial proliferation, segmental sclerosis). MCP-1 is produced locally in the kidney and plays an important role in the initiation and progression of renal damage, affecting particularly the tubulointerstitium..$^{[1]}$ Rafid Tofik et al revealed that urinary MCP-1 levels were significantly higher in patients with proliferative glomerulonephritis (IgA and mesangioproliferative) than in those with non-proliferative forms of glomerulonephritis (membranous, FSGS, and MCD) ${ }^{[10]}$ It is more likely that the level of urine MCP-1 reflect ongoing acute glomerular and tubular inflammation [13]. A study by Segerer S. et al demonstrated role of MCP-1 in renal inflammation and its induction of inflammatory signals. High urinary levels of CCL2/MCP-1 might indicate the presence and severity of glomerular injury in spite of the etiology ${ }^{[8]}$ In our study observed that urinary level of IL-6 positively correlated ( $\mathrm{p}$-value $=0.001,0.002$ and 0.009 in glomerulosclerosis, interstitial fibrosis and tubular atrophy respectively) with degree of glomerulosclerosis, interstitial fibrosis and tubular atrophy. A study by Maria Stangou et al showed that urinary excretion of IL-6 increased in parallel to severity of histological changes. Level of urinary IL-6 correlated with degree of glomerulosclerosis, interstitial fibrosis and tubular atrophy ${ }^{[12]}$ Urinary level of IL-6 may predict more accurately the severity of chronic tissue damage. Bergstein J. et al showed IL-6 involved in the formation of pathological changes of tubular atrophy, renal interstitial cell infiltration, mesangial cell proliferation and glomerulosclerosis. ${ }^{[14]}$

\section{Conclusion}

Idiopathic glomerulonephritis is common clinical entity seen in nephrology clinics. A good number of patients progress to ESRD. Early diagnosis and management of idiopathic glomerulonephritis can prevent the progression to ESRD. Though most of cases diagnosed on the clinical basis but for confirmation it requires renal biopsy which is an invasive procedure may leads to unwanted complication like hematuria, shock etc. Till now no specific biomarkers are available for diagnosis of idiopathic glomerulonephritis. In our study we evaluated urinary cytokines level in relation to histological severity of glomerular diseases. We found that level of urinary MCP-1 was raised in patients with increase degree of interstitial fibrosis and tubulointerstitial infiltrates and urinary IL-6 was noted in high level increase with increase degree of glomerlosclerosis, interstitial fibrosis and tublar atrophy. A large prospective study is recommended to confirm these findings. 


\section{References}

1. Rovin BH, Doe N, Tan LC Monocyte chemoattractant protein-1 levels in patients with glomerular disease. Am J Kidney Dis. 1996; 27: 640646.

2. Lepenies J, Eardley KS, Kienitz T, Hewison M, Ihl T, et al. Renal TLR4 mRNA expression correlates with inflammatory marker MCP-1 and profibrotic molecule TGF-beta in patients with chronic kidney disease. Nephron Clin Pract. 2011; 119: 97-104.

3. Kulkarni O, Pawar RD, Purschke W, Eulberg D, Selve N, et al. Spiegelmer inhibition of CCL2/MCP-1 ameliorates lupus nephritis in MRL- (Fas)lpr mice. J Am Soc Nephrol. 2007; 18: 2350-2358.

4. Hirano T, Akira S, Taga T, Kishimoto T. Biological and clinical aspects of interleukin-6. Immunol. Today 1990; 11: 443-49.

5. Frank J, Engler-Blum G, Rodemann HP, Muller GA. Human renal tubular cells as a cytokine source: PDGF-B, GM-CSF and IL-6 mRNA expression in vitro. Exp. Nephrol. 1993; 1: 26-35.

6. Tabata C, Kubo H, Tabata R et al. All-trans retinoic acid modulates radiation-induced proliferation of lung fibroblasts via IL-6/ IL-6R system. Am. J. Physiol. Lung Cell. Mol. Physiol. 2006; 290: 597-606

7. Ohta K, Takano N, Seno A et al. Detection and clinical usefulness of urinary interleukin-6 in the diseases of the kidney and the urinary tract. Cliii Nephrol. 1992; 38:185-189.

8. Ana Cristina Simõese Silva, André Barreto Pereira, MauroMartins Teixeira, and Antônio Lúcio Teixeira Chemokines as Potential
Markers in Pediatric Renal Diseases. Hindawi Publishing Corporation. Disease Markers. Volume 2014, Article ID 278715.

9. Hrvacevic R, Topalov D et al. Serum and urinary interleukin-6 levels in patients with primary glomerulonephritis. Srp Arh Celok. 1996; 124 suppl 1:40-2.

10. Rafid Tofik, Sophie Ohlsson, Omran Bakoush. Urinary Concentration of Monocyte Chemoattractant Protein-1 in Idiopathic Glomerulonephritis: A Long-Term Follow-Up Study. Plos one 2014 Jan 29; 9(1): e87857.

11. Minghui, Song Lu, Ma Dan et al. Clinical values of urinary IL-6 in asymptomatic hematuria and renal hematuria with proteins. Experimental and therapeutic medicine. 2013; 396-400.

12. 12.Stangou M, Alexopoulos E. et al Urinary levels of epidermal growth factor, interleukin-6 and monocyte chemoattractant protein-1 may

act predictor markers of renal function outcome in immunoglobulin A nep hro-pathy. Nephrology. 2009 Sep;14(6):613-20.

13. Bazzi C, Rizza V, Casellato D, Stivali G, Rachele G, et al. Validation of some pathophysiological mechanisms of the CKD progression theory and outcome prediction in IgA nephropathy. J Nephrol. 2012; 25: 810-818.

14. Bergstein $\mathbf{J}$, Leiser $\mathbf{J}$ and Andreoli $\mathrm{S}$ : The clinical significance of asymptomatic gross and microscopic hematuria in children. Arch Pediatr Adolesc Med 159: 353-355, 2005.

Copyright: () the author(s), 2019. It is an open-access article distributed under the terms of the Creative Commons Attribution License (CC BY 4.0), which permits authors to retain ownership of the copyright for their content, and allow anyone to download, reuse, reprint, modify, distribute and/or copy the content as long as the original authors and source are cited.

How to cite this article: Kar DP, Singh VP, Agarwal A, Ganiger VC, Mohanty JN. Evaluation of Urinary Cytokines in Idiopathic Glomerulonephritis in a Tertiary Care Teaching Hospital. Acad. J Med. 2019;2(2):68-72.

DOI: dx.doi.org/10.21276/ajm.2019.2.2.18

Source of Support: Nil, Conflict of Interest: None declared. 